\title{
Laser ablation synthesis and optical properties of copper nanoparticles - ERRATUM
}

Amir Reza Sadrolhosseini, Ahmad Shukri Bin Muhammad Noor, Kamyar Shameli, Ghazaleh Mamdoohi, Mohod Maarof Moksin, and Mohod Adzir Mahdi

doi: 10.1557/jmr.2013.244, Published by Materials Research Society with Cambridge University Press, 30 August 2013.

In Sadrolhosseini et al. ${ }^{1}$, page 6, second column, first line: $1.44371+0.0034$ should be $1.44371+$ $0.0034 \mathrm{i}$.

The publisher regrets the mistake.

\section{REFERENCE}

1. A.R. Sadrolhosseini, A.S.B.M. Noor, K. Shameli, G. Mamdoohi, M.M. Moksin, and M.A. Mahdi: Laser ablation synthesis and optical properties of copper nanoparticles. J. Mater. Res. 28(18), 1316-1325 (2013). 